Effects of live music therapy on heart rate variability and self-reported stress and anxiety among hospitalized pregnant women : A randomized controlled trial

\title{
Teckenberg-Jansson, Pia
}

2019

Teckenberg-Jansson, P , Turunen , S , Pölkki , T , Lauri-Haikala , M-J , Lipsanen , J , Henelius , A , Aitokallio-Tallberg , A , Pakarinen , S , Leinikka , M \& Huotilainen , M 2019 , ' Effects of live music therapy on heart rate variability and self-reported stress and anxiety among hospitalized pregnant women : A randomized controlled trial ' , Nordic Journal of Music Therapy , vol. 28 , no. 1 , pp. 7-26 . https://doi.org/10.1080/08098131.2018.1546223

http://hdl.handle.net/10138/311195

https://doi.org/10.1080/08098131.2018.1546223

publishedVersion

Downloaded from Helda, University of Helsinki institutional repository.

This is an electronic reprint of the original article.

This reprint may differ from the original in pagination and typographic detail.

Please cite the original version. 


\section{Effects of live music therapy on heart rate variability and self-reported stress and anxiety among hospitalized pregnant women: $A$ randomized controlled trial}

Pia Teckenberg-Jansson, Siiri Turunen, Tarja Pölkki, Minna-Johanna LauriHaikala, Jari Lipsanen, Andreas Henelius, Ansa Aitokallio-Tallberg, Satu Pakarinen, Marianne Leinikka \& Minna Huotilainen

To cite this article: Pia Teckenberg-Jansson, Siiri Turunen, Tarja Pölkki, Minna-Johanna LauriHaikala, Jari Lipsanen, Andreas Henelius, Ansa Aitokallio-Tallberg, Satu Pakarinen, Marianne Leinikka \& Minna Huotilainen (2019) Effects of live music therapy on heart rate variability and selfreported stress and anxiety among hospitalized pregnant women: A randomized controlled trial, Nordic Journal of Music Therapy, 28:1, 7-26, DOI: 10.1080/08098131.2018.1546223

To link to this article: https://doi.org/10.1080/08098131.2018.1546223

View supplementary material $๘$ 曲 Published online: 24 Jan 2019.

Submit your article to this journal $\widetilde{ }$

Џll Article views: 382

View related articles ¿

View Crossmark data $\nearrow$

Citing articles: 1 View citing articles $\sqsubset$ 


\title{
Effects of live music therapy on heart rate variability and self-reported stress and anxiety among hospitalized pregnant women: A randomized controlled trial
}

\author{
Pia Teckenberg-Jansson ${ }^{a}$, Siiri Turunen ${ }^{b}$, Tarja Pölkkic, Minna-Johanna Lauri- \\ Haikalab , Jari Lipsanen ${ }^{\mathrm{b}}$, Andreas Henelius ${ }^{\mathrm{d}, \mathrm{e}}$, Ansa Aitokallio-Tallbergf, \\ Satu Pakarinen ${ }^{\mathrm{d}}$, Marianne Leinikka ${ }^{\mathrm{d}}$ and Minna Huotilainen ${ }^{\mathrm{b}}$
}

a ävelvoima-Tonkraft, Västerskog, Finland; ${ }^{b}$ CICERO Learning Network, Faculty of Educational Sciences and Cognitive Brain Research Unit, Department of Psychology and Logopedics, Faculty of Medicine, University of Helsinki, Helsinki, Finland; 'Department of Children and Women, Oulu University Hospital, Oulu, Finland; 'Finnish Institute of Occupational Health, Helsinki, Finland; eDepartment of Computer Science, University of Helsinki, Helsinki, Finland; 'Department of Obstetrics and Gynecology, Helsinki University Hospital, University of Helsinki, Helsinki, Finland

\begin{abstract}
Introduction: This study aims to evaluate the effects of live music therapy on heart rate variability (HRV) and self-reported stress and anxiety among hospitalized women with high-risk pregnancies. A total of 102 women at an antenatal ward due to pregnancyrelated complications participated in a randomized controlled trial.

Methods: The participants were randomly assigned to a music therapy group $(N=52)$ or control group $(N=50)$. The women in the music therapy group received live music therapy on three consecutive days, for half an hour at a time. The participants belonging to the control group were instructed to rest for equally long time periods. The physiologic stress of the participants was assessed using HRV measures. The participants also rated their perceived stress and anxiety. The physiologic stress of the participants was assessed using 12 HRV measures.

Results: The SD2 measure of HRV increased significantly more in the music therapy group than in the control group during the therapy sessions. Moreover, the low frequency (LF) HRV measure decreased during the three-day therapy period. The self-reported stress was not significantly altered after the intervention. For women with high initial self-reported anxiety in both groups, their anxiety was significantly reduced during the three-day period.
\end{abstract}

ARTICLE HISTORY Received 9 September 2017; Accepted 26 October 2018

KEYWORDS Prenatal stress; prenatal anxiety; live music therapy; pregnancy complications; heart rate variability (HRV)

\section{Introduction}

Research over the last three decades has established that women experiencing high stress and anxiety during pregnancy are at risk of preterm birth and miscarriage

CONTACT Pia Teckenberg-Jansson pia.teckenberg@kolumbus.fi @ Sävelvoima-Tonkraft, Stuvunäsvägen 11, 01120 Västerskog, Finland; Minna Huotilainen minna.huotilainen@helsinki.fi $\Theta$ CICERO Learning Network, Faculty of Educational Sciences, P.O. Box 9, 00014 University of Helsinki, Finland.

(4) Supplementary data for this article can be accessed here. 
(Dole et al., 2003; Douglas, 2010; Lobel et al., 2008; Mulder et al., 2002). Preterm born children with low birth weight may suffer from long-term health problems such as neurodevelopmental disorders (Soleimani, Zaheri, \& Abdi, 2014) and later depression (Räikkönen et al., 2008). High antenatal maternal stress and anxiety is related to regulation problems at the cognitive, behavioral, and emotional levels. Further, stress and anxiety may interfere with fetal development, even increasing the risk for severe lifelong diseases (Douglas, 2010; Van Den Bergh, Mulder, Mennes, \& Glover, 2005). Maternal stress has also been shown to have a causal connection to fetal stress as reduced fetal HRV (DiPietro, Hodgson, Costigan, Hilton, \& Johnson, 1996).

Pregnancy-specific stress is indicated to be a more powerful contributor to birth outcomes than general stress (Lobel et al., 2008), and having a high-risk pregnancy increases the impact of stress (Geller, 2004). Notably, hospitalized pregnant women treated with bed rest have a considerably higher risk of experiencing anxiety and stress (Maloni \& Park, 2005). Physical and emotional changes during pregnancy, in addition to the concerns about parenting, changing family relationships, labor, and the child's health, may produce stress for pregnant women (Chang, Chen, \& Huang, 2008, Lobel et al., 2008). Prenatal stress and anxiety should be seriously considered in health care due to its consequences for fetal development and well-being (Dennis, Falah-Hassani, \& Shiri, 2017; Graignic-Philippe \& Tordjman, 2009; Van Den Bergh et al., 2005). Consequently, there is an essential need for stress relief during pregnancy.

Non-pharmacological interventions have been developed specifically for the care of pregnant women, since pharmacological treatments may pose serious risks for both the mother and fetus (Calderon-Margalit, Qiu, Ornoy, Siscovick, \& Williams, 2009; Chang et al., 2008). Bed rest is often prescribed for women with high-risk pregnancies but may result in adverse physical and psychological consequences such as fatigue, backache, and depression, which may continue after the child is born (Maloni \& Park, 2005). Maternal relaxation may be beneficial for the fetus and lead to decreased fetal heart rate, increased fetal HRV and suppression of fetal motor activity (Dipietro, Costigan, Nelson, Gurewitsch, \& Laudenslager, 2008). Significant prolongation of pregnancy can be achieved through a relaxation training program for hospitalized pregnant women (Chuang et al., 2012a). Beneficial effects of relaxation on reducing self-reported anxiety and stress in pregnant women have also been found (Bastani, Hidarnia, Kazemnejad, Vafaei, \& Kashanian, 2005).

Music is widely known to enhance well-being, reduce stress and distract patients from unpleasant symptoms by exerting direct physiological effects through the autonomic nervous system (Kemper \& Danhauer, 2005). Listening to relaxing music lowers perceived stress levels, as indicated by reduced cortisol levels, lowered heart rate, and lowered mean arterial pressure (Burrai, Hasan, Fancourt, Luppi, \& DiSomma, 2016; Lai \& Li, 2011). Bieligmeyer (2015) studied the effects of the Tao sound-bed (Benedek) on oncology patients and found significant changes of inner balance, vitality, and vigilance. Gilboa (2014) studied the uterine auditory environment and its effects on the fetus. Mothers listening to music during pregnancy experienced lower levels of psychosocial stress; music particularly alleviated the stress related to future baby care, changing family relationships, and the maternal role identification (Chang, Yu, Chen, \& Chen, 2015). 
Music therapy has previously been used in the care of pregnant women, but only a few studies have investigated whether music therapy relieves pregnancyrelated stress and anxiety (Bauer, Victorson, Rosenbloom, Barocas, \& Silver, 2010; Carolan, Barry, Gamble, Turner, \& Mascareñas, 2012; Chang et al., 2008; Collins Cook, 2012; Kaufmann, 2014). The findings of Chang et al. (2008) show that listening to soothing music for half an hour daily significantly decreased stress, anxiety and depression after a two-week period. Bauer et al. (2010) found that live music and recreation therapy significantly reduced antepartum-related distress in women hospitalized with high-risk pregnancies. In a similar context, Nussberger (2014) found short-term live music therapy to be relaxing. Listening to music has also been found to increase satisfaction with nursing care: blood pressure was reduced but did not have a significant effect on anxiety in pregnant women with preeclampsia (Toker \& Kömürcü, 2017). Sidorenko (2000) studied medical resonance therapy in treatment of women with high-risk pregnancies and found that a ten-day music intervention reduced the rate of premature births, reduced stress and cortisol levels, and lowered the heart rate. Moreover, the women slept better and needed fewer painkillers, and systolic blood pressure was reduced for those whose blood pressure was initially high. A recently published review and metaanalysis evaluated the effectiveness of music-based interventions, and indicated reductions in levels of stress and anxiety among pregnant women (Corbijn van Willenswaard et al., 2017).

Music therapy may contain live or recorded music, and some studies have compared the effects of these variations on hospitalized patients (Arnon et al., 2006; Bailey, 1983; Garunkstiene, Buinauskiene, Ingrida Ulozienec, \& Markuniene, 2014). According to these studies, live music therapy would be more effective and beneficial for the patient. However, the effects of live music therapy on the HRV and self-reported stress and anxiety among hospitalized pregnant women have not been previously studied.

We empirically studied the novel problem of how live music therapy affects HRV and self-reported stress and anxiety among hospitalized pregnant women. According to our hypothesis, women receiving live music therapy have higher HRV than the women in the control group, and repetition enhances the effect of music therapy. Second, we hypothesize that music therapy reduces the levels of selfreported stress and anxiety more than resting. Third, we hypothesize that women who initially are more anxious, will benefit more from the music therapy. Furthermore, we wanted to investigate whether the first and the second half of the music therapy session might affect HRV measures differently.

\section{Methods}

\section{Study design}

The study was designed as a randomized controlled trial (RCT). On the first day of the experiment the pregnant women on the ward received a detailed explanation of the goals and procedures of the study, and thereafter gave signed informed consent. The participants were then randomly assigned to either the music therapy group $(N=52)$ or the control group $(N=50)$. The music therapist performed the allocation 
by drawing lots. Only the music therapist saw the randomization list, and it was stored according to the Ethical Approval. The random assignment into groups was performed before any data collection (e.g. questionnaires on stress and anxiety levels, or physiologic data) took place, and the group assignment was not altered during the course of the study. The music therapy group received live music therapy on three consecutive days, for half an hour at a time. The women in the control group were instructed by the music therapist to rest in their bed for comparable time periods and were left alone during this time. The music therapist informed the participants in the control group when the time of rest started and ended. The instruction to rest was in conjunction with the instructions given by the physician and the nurses at the ward: to spend time in the bed and try to find a comfortable resting position. The experienced levels of stress and anxiety were measured with Perceived Stress Scale (PSS) and State Scale of the State-Trait Anxiety Inventory (S-STAI). The participants completed the questionnaires both before and after the intervention. The physiological stress levels of the participants were assessed by measuring their HRV.

\section{Participants and settings}

The participants of the study $(N=102)$ were pregnant women (mean age 31 years, range 18-47) who were hospitalized due to pregnancy-related complications. Sample size estimate was based on previous work in the field, reporting significant findings with similar groups of participants (Bauer et al., 2010; Chuang et al., 2012b; Toker \& Kömürcü, 2017; Yang et al., 2009) and on the estimated number of participating patients on the ward. The study included all the volunteers that matched the eligibility criteria: (1) a minimum age of 18 years, (2) the prospect of spending four or more days in inpatient care (estimated by a nurse), and (3) fluent speaker of Finnish or Swedish. Altogether 148 participants were screened for eligibility. Forty-six women declined to participate in the study. The most common reason for declining was that the mother felt unable or unwilling to concentrate on anything new because of the stressful circumstances. Some mothers declined due to unwillingness to wear the measurement device (Figure 1).

The study took place on the antenatal ward at the Helsinki University Hospital in Finland from April 2013 until November 2014. The ward has 19 beds for antenatal and labor induction patients. Patients were admitted to the ward due to various problems related to pregnancy. The most common diagnosis was the risk of premature delivery. These patients had for instance premature rupture of membranes or uterine contractions with shortened cervix. Both pregnancies with singletons and twins were represented. Other subgroups were women with hypertensive problems like preeclampsia, fetal growth restriction from different origins, antenatal bleeding and maternal diabetes. The average stay on the ward was 3 days. We were not able to collect the individual medical records of the women participating in our study, but we estimated that there was no difference between the therapy and control groups in the reasons for admission to the ward. Thus, the characteristics of the pregnancy complications are unlikely to have interfered with the results.

\section{Permission for the study}

The study complies with the Declaration of Helsinki and was approved by the Ethical committee of Women and Child Psychiatry in the Hospital District of Helsinki and 


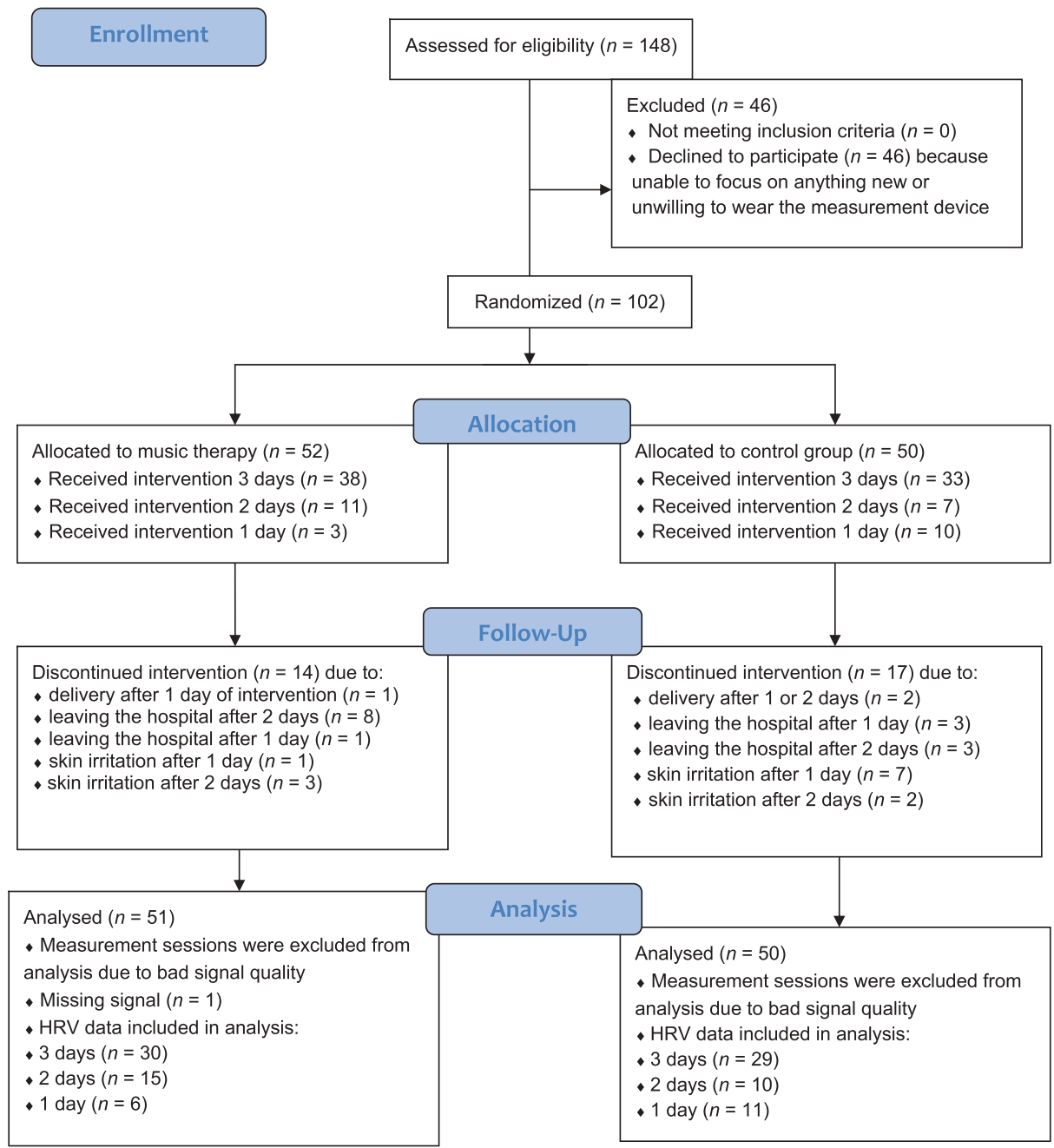

Figure 1. Flow chart of participant enrollment.

Uusimaa (391/13/03/03/2012). The research permission was granted by the department of Women and Children Diseases of the Helsinki University Central Hospital, Hospital District of Helsinki and Uusimaa (Permission: 07.03.2013). Each participant was informed both orally and in writing regarding the course of the study, that the collected data would be recorded anonymously, and that their personal information would be kept confidential. The participants were encouraged to ask for more information at any time. Written informed consent was obtained from all participants.

\section{Intervention}

In anthroposophical music therapy, the lyre is used as an instrument that addresses the middle part of the human being in a way that is liberating and enhances a more 
inward experience (Reinhold, 2012). Its gently resounding tone quality can encourage general relaxation and relieve congested breathing, pain and tension. The sound of the lyre is gentle, soft and pleasantly enveloping. It opens up a space for sensitive listening and creates a calm atmosphere.

This research included two different lyre instruments: a seven-stringed pentatonic Auris children's lyre from Sweden (http://auris-musical-instruments.com/lyres) and a Tao-lyre built by R. Benedek, Germany (https://www.aeterherz.de/startseite/english/). The word tao signifies the primordial essence or fundamental nature and balance of the universe. Inspired by the Austrian philosopher Dr. Rudolf Steiner, the Tao-lyre was created as a therapeutic instrument by a music therapist Victoria Ryan in Vienna and a German constructor of instruments Andreas Lehmann. The Tao-lyre, a vibroacoustic instrument, has 48 strings but only four tones: b, a, e, d. Each tone has three strings and the tones extend over four octaves. The sound level of these lyres is 5-68 $\mathrm{dB}$. In a therapy session the sound intensity is adjusted individually to each patient for a comfortable level, and kept between 10 and $35 \mathrm{~dB}$.

The live music therapy included playing of the two lyre instruments and humming beside the bed of the patient. The duration and intensity of the intervention was planned by a trained and experienced music therapist, who took into account her experiences of the needs and preferences for music therapy in pregnant women, and the information of the mean stay of the patients of the ward. The music was adjusted individually to avoid any kind of overstimulation and the participants were asked if they had a favorite lullaby. First, the pentatonic lyre was placed and played on the abdomen of the patient who was comfortably lying on her back. Lullabies were hummed according to the patient's wishes. The patients were also encouraged to hum along and after the first half of the therapy session they were offered the opportunity to play the lyre themselves, however, only a few were willing to do so. Thereafter, the music therapist played the Tao-lyre positioned on the legs of the participant. After that, the patient turned to lie on her side, and the Tao-lyre was played against her back. The lyre was touching the body so that the sound would resonate stronger within the body. The resonance and the sound of the lyre helped the women to focus on their own body and the baby. This offered them an opportunity to become aware of breathing and possible tensions. Four of the participants did not wish the lyre to touch their bodies, and therefore the lyre was played by their side.

\section{Outcomes}

HRV refers to the alteration in time between consecutive heart beats (Berntson et al., 1997). HRV was calculated from the electrocardiogram (ECG) recorded at $1000 \mathrm{~Hz}$ using a single lead (two electrodes) with the Firstbeat Bodyguard device (Firstbeat Technologies). The goal of HRV analysis is to investigate the natural, minor variations in the heart rhythm. The basis for the analysis is a so-called RR (interbeat) interval time series derived from the ECG, describing the time (in milliseconds) between successive R-peaks in the ECG waveform. On the first day of the study, the device was attached by the music therapist to the skin of the patient: one electrode below the right clavicle and the other electrode on the lower left rib cage. The data was recorded continuously during the three days of the study and the device was to 
remain in place, except during showering. After the three-day period, the device was removed.

HRV data was collected from a total of 102 participants. The full three-day data set was available from 71 participants. Of the participants in the music therapy group 38 women received the intervention during 3 days, 11 women during 2 days and 3 women during 1 day. In the control group the corresponding numbers were 33 women during 3 days, 7 women during 2 days and 10 women during 1 day. The 31 dropouts were mostly due to the experiment ending in delivery ( 3 women) or the mother leaving the hospital (15 women) and in 13 cases due to skin irritation caused by the ECG electrodes.

The participants were asked to provide personal information on a questionnaire which consisted of nine questions concerning their age, the gestational age of the fetus, their education, profession, earlier pregnancies, number of children, reason for hospitalization, diagnosis, and the date of arrival at the hospital.

A shortened, 5-item version of The Perceived Stress Scale (PSS; Cohen, Kamarck, \& Mermelstein, 1983; Pesonen et al., 2008) was used to evaluate the participants' selfreported stress level before and after the intervention. The questions included for instance: "In the past two weeks, how often have you felt that things were going your way?," "How often have you felt that you were unable to control the important things in your life?," and "How often have you felt nervous and stressed?" The responses were given on a 5 -point Likert scale ( $1=$ never, $5=$ very often $)$.

Self-reported anxiety before and after the intervention was evaluated with The State-Trait Anxiety Inventory (STAI, Spielberger, Gorsuch, \& Lushene, 1970). The questionnaire is composed of 20 items each making a statement, such as "I feel calm," "I am worried," and "I feel confused."Half of the statements describe positive feelings ("I feel comfortable"), and the other half negative ("I feel frightened"). The participants were instructed to mark on a 4-point Likert scale how much they agreed with the statement at that moment $(1=$ not at all, $4=$ very much so $)$.

\section{Data preprocessing and statistical analysis}

The analyses were made using R (version 3.1.1 GUI 1.65 Mavericks build; R Core Team, 2014). The colibri R-package (Henelius, 2014) was used to analyze the HRV data. The sessions of music therapy (or rest in the control group) lasted 20-30 min and the HRV was analyzed from these periods. Artifacts were automatically removed using the method by $\mathrm{Xu}$ and Schuckers (2001). On the basis of visual inspection of the data, ten measurement sessions (i.e. therapy or rest sessions) were removed due to bad signal quality.

The data from each session was divided into segments with a length of $2.5 \mathrm{~min}$. The segment length was chosen to be shorter than the usual five minutes in order to minimize the effects of motion artifacts due to the participant changing her position. During late pregnancy, and especially during compromised pregnancies as experienced by the participants of this study, the comfortable position of the mother is of extreme importance. For this reason, participants wanted to change their position often. The data segments in which the maximum heart rate exceeded the mean value of the data from the full measurement session by more than two standard deviations (SD) were excluded from the analysis as they would likely contain excessive noise and/or artifacts. For each included segment, timedomain, frequency-domain and geometric HRV metrics were computed. The time domain 
metrics were: mean heart rate (i.e. beats per minute), median heart rate, RMSSD (rootmean square of successive RR-interval differences), SDNN (standard deviation of normal RR-intervals), and pNN50 (the proportion of pairs of successive normal-to-normal RRintervals differing more than $50 \mathrm{~ms}$ ). The frequency-domain metrics were estimated using the Lomb-Scargle periodogram (Scargle, 1982). The frequency domain metrics were: power in the low-frequency (LF: 0.04-0.15 Hz) and high-frequency (HF: 0.15-0.4 Hz) bands, commonly used in HRV analyses (Task Force of the European Society of Cardiology and the North American Society of Pacing and Electrophysiology, 1996). The ratio of power in the LF to $\mathrm{HF}$ band $(\mathrm{LF} / \mathrm{HF})$ was also computed. Additionally, the normalized values of both LF and HF were calculated. The geometric metrics used were Poincaré plot indices, SD1 and SD2. The Poincaré plot is a visualization of the HRV signal in which each RR-interval is plotted against the preceding RR-interval. A common technique is to fit an ellipse to the shape of the Poincaré plot, where the dispersions (or standard deviations) along the minor and major axis of the ellipse are referred as SD1 and $\mathrm{SD} 2$, respectively. SD1 is known to describe short-term and SD2 long-term variability of

Table 1. Description of different HR and HRV metrics measured during the sessions.

\begin{tabular}{|c|c|c|c|c|c|}
\hline Metric & Unit & Description & Reflects & $\begin{array}{l}\text { Indication of } \\
\text { relaxation (e.g. } \\
\text { low mental } \\
\text { stress) }\end{array}$ & Reference \\
\hline $\begin{array}{r}\text { Mean } \\
\text { HR }\end{array}$ & bpm & Mean heart rate & $\begin{array}{l}\text { Relative balance } \\
\text { between sympathetic }\end{array}$ & Lower values & $\begin{array}{l}\text { Taelman, } \\
\text { Vandeput }\end{array}$ \\
\hline $\begin{array}{l}\text { Median } \\
\text { HR }\end{array}$ & bpm & Median heart rate & $\begin{array}{l}\text { and parasympathetic } \\
\text { systems }\end{array}$ & & $\begin{array}{l}\text { Vleminck, } \\
\text { Spaepen, \& Van } \\
\text { Huffel, } 2011\end{array}$ \\
\hline SDNN & $\mathrm{ms}$ & $\begin{array}{l}\text { Standard deviation of } \\
\text { normal-to-normal RR- } \\
\text { intervals }\end{array}$ & Total HRV & Higher values & $\begin{array}{l}\text { Taelman et al., } \\
2011\end{array}$ \\
\hline RMSSD & $\mathrm{ms}$ & $\begin{array}{l}\text { Root-mean square of } \\
\text { successive RR-interval } \\
\text { differences }\end{array}$ & $\begin{array}{l}\text { Parasympathetic } \\
\text { activity }\end{array}$ & Higher values & $\begin{array}{l}\text { Taelman et al., } \\
2011\end{array}$ \\
\hline pNN50 & $\%$ & $\begin{array}{l}\text { Proportion of pairs of } \\
\text { successive normal-to-normal } \\
\text { RR- intervals differing more } \\
\text { than } 50 \mathrm{~ms}\end{array}$ & $\begin{array}{l}\text { Parasympathetic } \\
\text { activity }\end{array}$ & Higher values & $\begin{array}{l}\text { Taelman et al., } \\
2011\end{array}$ \\
\hline $\mathrm{LF}$ & $m s^{2}$ & $\begin{array}{l}\text { Power in low-frequency band } \\
(0.04-0.15 \mathrm{~Hz})\end{array}$ & $\begin{array}{l}\text { Both sympathetic and } \\
\text { parasympathetic }\end{array}$ & Lower values & $\begin{array}{l}\text { Delaney \& Brodie, } \\
\quad 2000\end{array}$ \\
\hline LF.n & - & $\begin{array}{l}\text { Normalized value of } L F \\
L F . n=L F /(L F+H F)\end{array}$ & activities & & \\
\hline HF & $m s^{2}$ & $\begin{array}{l}\text { Power in high-frequency } \\
\text { band }(0.15-0.4 \mathrm{~Hz})\end{array}$ & $\begin{array}{l}\text { Parasympathetic } \\
\text { activity }\end{array}$ & Higher values & $\begin{array}{l}\text { Delaney \& Brodie, } \\
2000\end{array}$ \\
\hline HF.n & - & $\begin{array}{l}\text { Normalized value of } H F \\
\text { HF. } n=H F /(H F+L F)\end{array}$ & & & \\
\hline LF/HF & - & $\begin{array}{l}\text { The ratio of power in LF to } \\
\text { HF band }\end{array}$ & $\begin{array}{l}\text { Sympatho-vagal } \\
\text { balance }^{a}\end{array}$ & Lower values & $\begin{array}{l}\text { Delaney \& Brodie, } \\
\quad 2000\end{array}$ \\
\hline SD1 & $\mathrm{ms}$ & $\begin{array}{l}\text { Poincaré plot index - } \\
\text { Standard deviation of short- } \\
\text { term RR-interval variability }\end{array}$ & $\begin{array}{l}\text { Parasympathetic } \\
\text { activity }\end{array}$ & Higher values & $\begin{array}{l}\text { Melillo, Bracale, \& } \\
\text { Pecchia, } 2011\end{array}$ \\
\hline SD2 & ms & $\begin{array}{l}\text { Poincaré plot index - } \\
\text { Standard deviation of long- } \\
\text { term RR-interval variability }\end{array}$ & $\begin{array}{l}\text { Both sympathetic and } \\
\text { parasympathetic } \\
\text { activities }\end{array}$ & Higher values & Melillo et al., 2011 \\
\hline
\end{tabular}

\footnotetext{
a Widely accepted to describe the sympatho-vagal balance. However, this view has also been increasingly
} challenged, see more, e.g. Eckberg (1997) and Billman (2013). 
the RR intervals. The common behavior of the different HR and HRV metrics during relaxation is reviewed in Table 1 (see also review article Shaffer \& Ginsberg, 2017). When interpreting the results, it is important to note that many of the HRV metrics strongly correlate with each other (Task Force of the European Society of Cardiology and the North American Society of Pacing and Electrophysiology, 1996). Especially, in individuals without heart problems the calculation of SD1 and SD2 produce very similar, or identical values to RMSSD and SDNN respectively (Brennan, Palaniswami, \& Kamen, 2001; Carrasco, Gaitán, González, \& Yánez, 2001; Karmakar, Khandoker, Gubbi, \& Palaniswami, 2009). Also, the frequency measures typically correlate strongly with each other [e.g., $R$ $\left(\mathrm{HF}^{\star} \mathrm{LF}\right)=0.53, p<.01$, Tulppo, Makikallio, Takala, Seppanen, and Huikuri (1996)] and the non-normalized variables of HRV are more strongly correlated with HR than normalized values (Sacha, 2013; for a comprehensive representation of correlations between HRV metrics measured at rest, see Tulppo et al., 1996). Therefore, to avoid increase of type II errors, the results are reported with no corrections for multiple testing (see, for instance, the review by Sinclair, Taylor, \& Hobbs, 2013).

Linear mixed models were employed for statistical comparisons using the lme4 R-package (Baayen, Davidson \& Bates, 2008). The dependent variable of the model was a HRV metric (with separate models for each HRV measure). Group (music therapy/control), measurement day $(1,2,3)$, segment and age were included in the model as independent fixed effects, and participant was included as the random effect. The significance of the interaction was tested using likelihood ratio tests by comparing the model with and without the interaction. Further, the car R-package was used to calculate the Wald chi-square test results reported below in the result section.

The within-group (therapy or control) differences in state anxiety and stress before and after the study were assessed using paired sample $t$-tests.

Next, the sample was divided into two subsamples based on the self-reported state anxiety in the beginning of the experiment: score 40 or more representing high state anxiety and 39 or under representing moderate state anxiety (Spielberger, Gorsuch, Lushene, Vagg, \& Jacobs, 1983; Lin, Hsieh, Hsu, Fetzer, \& Hsu, 2011). The highanxiety group included 70 participants (39 in the music therapy group), and the moderate-anxiety group included 31 participants (13 in the music therapy group).

The repeated measures $t$-test was employed to compare the two subsamples with respect to the effects of the music therapy on perceived stress and anxiety. This analysis was also conducted for the two subsamples (two separate models).

\section{Results}

\section{Background information}

Table 2 shows the participants' background information that was collected for the study. The groups did not significantly differ in terms of age, duration of the pregnancy, education, or number of children. The initial self-reported anxiety in the music therapy group was slightly higher than in the control group. The perceived stress estimates measured with the PSS did not differ before the intervention. Moreover, in the highly anxious subgroup, the music therapy group contained more participants who were able to participate in only two out of three sessions. 
Table 2. Group-level background information of participants included in the study.

\begin{tabular}{|c|c|c|c|c|}
\hline Variable & Music therapy & Control & & \\
\hline \multirow[t]{2}{*}{$N$} & 52 & 50 & & \\
\hline & Mean $(S D)$ & Mean $(S D)$ & $t$ value & $p$ value \\
\hline Age & $30.6(6.9)$ & $31.0(5.4)$ & 0.39 & .70 \\
\hline Gestational age (in weeks) & $28.7(3.1)$ & $28.2(3.4)$ & 0.89 & .37 \\
\hline Perceived stress $\left(\right.$ PSS) ${ }^{a}-$ Pre & $3.0(0.8)$ & $2.7(0.7)^{\mathrm{c}}$ & 1.76 & .08 \\
\hline Perceived stress (PSS) ${ }^{\mathrm{a}}-$ Post & $2.9(0.8)$ & $2.7(0.7)$ & 0.93 & .36 \\
\hline Symptoms of anxiety (S-STAI) ${ }^{\mathrm{b}}-$ Pre & $2.4(0.6)$ & $2.2(0.5)^{c}$ & 2.20 & $.03^{*}$ \\
\hline \multirow{2}{*}{$\begin{array}{l}\text { Symptoms of anxiety (S-STAI) }{ }^{\text {b }}-\text { Post } \\
\text { Education }\end{array}$} & $2.2(0.6)$ & $1.9(0.4)$ & 2.47 & $.02 *$ \\
\hline & $N(\%)$ & $N(\%)$ & & \\
\hline Basic education & $4(7.7)$ & $3(6.0)$ & & \\
\hline Upper secondary level & $22(42.3)$ & $20(40.0)$ & & \\
\hline Lower academic degree & $12(23.1)$ & $12(24.0)$ & & \\
\hline Higher academic degree & $13(25.0)$ & $11(22.0)$ & & \\
\hline Missing information & $1(1.9)$ & $4(8.0)$ & & \\
\hline \multicolumn{5}{|l|}{ Number of children } \\
\hline 0 & $28(53.8)$ & $23(46.0)$ & & \\
\hline 1 & $18(34.6)$ & $17(34.0)$ & & \\
\hline 2 & $5(9.6)$ & $7(14.0)$ & & \\
\hline 3 & $1(1.9)$ & $3(6.0)$ & & \\
\hline
\end{tabular}

a Shortened, five-item version of the Perceived Stress Scale.

b The State-Trait Anxiety Inventory.

c Data from 49 participants.

* $p<.05$.

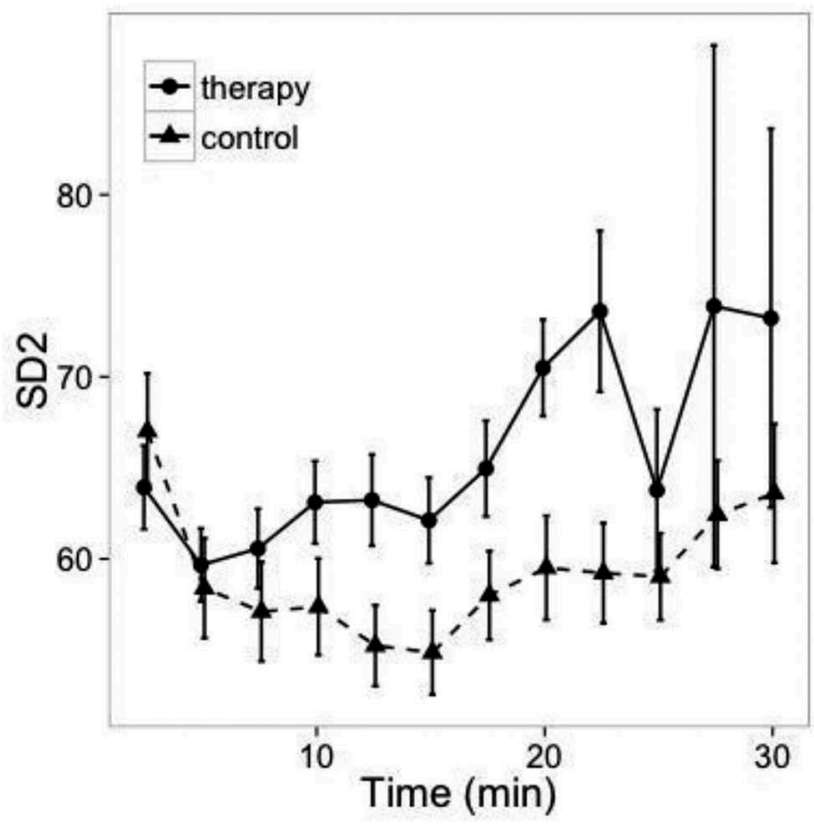

Figure 2. Changes in SD2 of the heart rate during a therapy or a control session.

Note. The figure shows the mean values of the SD2 (a nonlinear, geometric parameter reflecting the deviation of the heart rate) during a therapy or a control session. The error bars illustrate the standard error of mean (SEM). Higher SD2 values are generally related to more relaxation (Table 1). Corresponding changes in the other 11 HRV measures are shown in Supplemental Figure 2. 


\section{Heart rate variability}

The linear mixed effects modeling showed that 10 of $12 \mathrm{HR} / \mathrm{HRV}$ measures did not show significant effects. The significant effects were the following: SD2 increased more during the therapy sessions than during the control (rest) sessions $\left[\chi^{2}(2)=4.9\right.$, $\mathrm{p}=.027$; Figure 2]. The HF increased more in the control condition than in the therapy condition $\left[\chi^{2}=8.31, p=.004\right]$, but the interaction was not significant with normalized (HF.n) values $\left[\chi^{2}=1.33, p=.25\right]$. With Bonferroni adjustment the effect on SD2 is not significant.

Comparing the three sessions, 7 of the $12 \mathrm{HRV}$ metrics did not show significant differences. The significant effects were as follows: SDNN was more decreased in later sessions of the therapy group than in the control group $\left[\chi^{2}=12.3, p=.002\right]$. Moreover, the SD2 decreased from a session to another in the therapy group $\left[\chi^{2}(2)=11.4, p=.003\right]$. The LF decreased between the sessions in the therapy group more than in the control group $\left[\chi^{2}(2)=12.7, p=.002\right.$; Figure 3]. The normalized values (LF.n) also showed significant differences $\left[\chi^{2}(2)=7.73, p=.02\right]$. HF.n slightly increased between the sessions in the therapy group, whereas it slightly decreased between the sessions in the control group $\left[\chi^{2}(2)=7.73, p=.02\right]$. With Bonferroni adjustment the effects on LF.n is not significant. The other HRV outcomes between therapy sessions (Supplemental Table 1 and Supplemental Figure 1) and during a therapy session (Supplemental Table 2 and Supplemental Figure 2) are presented in the supplemental information of the study.

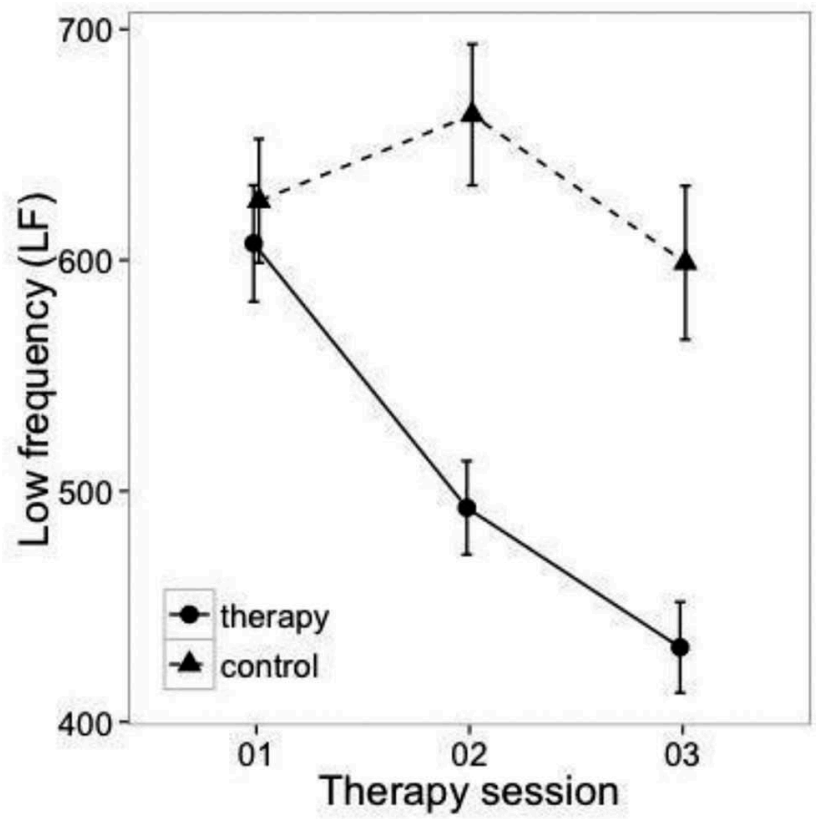

Figure 3. Changes in LF of the heart rate over three therapy or control sessions.

Note. The low frequency (LF) variation of the heart rate. Mean values ( \pm SEM) in the three therapy or control sessions. Corresponding changes in the other 11 HRV measures are shown in Supplemental Figure 1. 


\section{Stress}

The paired sample $t$-test showed that the stress did not differ significantly within the therapy and control groups before and after the intervention: music therapy group $t$ $(1,42)=-1.31$, ns. and control group $t(1,35)=0.30$, ns.

\section{Anxiety}

The $t$-tests revealed that in the entire study sample, the state anxiety was significantly reduced during the study period, on average by 6.2: $t(1,60)=5.016, p<0.001$ (twotailed). Further, when the therapy and control groups were separately examined, the state anxiety was significantly reduced in both groups: music therapy group $t(1,31)=3.10, p<0.004$ (two-tailed) and control group $t(1,28)=4.11, p<0.000$ (twotailed). When the amount of change in state anxiety (before-minus-after treatment) was compared between groups, there was no significant group difference $[F$ $(1,59)=1.707, p=.73$ ]. In the control group the mean anxiety score was -1.27 before the intervention and -7.93 after the intervention, that is, the mean anxiety decreased with 6.66. The women in the therapy group had a mean score 2.09 and the anxiety decreased after the intervention (mean score -3.69 ), showing a reduction of 5.78 units.

For the highly anxious participants, SDNN increased within a therapy session $[F$ $(1,1516)=4.44, p=.04]$. For the moderately anxious participants, mean HR decreased within a therapy session $[F(1,690)=9.52, p=.02]$. HRV metrics of the highly anxious participants did not differ between therapy sessions. However, in the moderately anxious group, mean HR, RMSSD, and pNN50 differed between the therapy and control sessions. Figure 4 shows that the second therapy and control sessions differed from the first and the third sessions.

The level of self-reported anxiety of the highly anxious participants was reduced both in the music therapy $[t(31)=3.74, p<.001]$ and control groups $[t(22)=4.09$, $p<.001]$, but there was no difference in the magnitude of the reduction between the
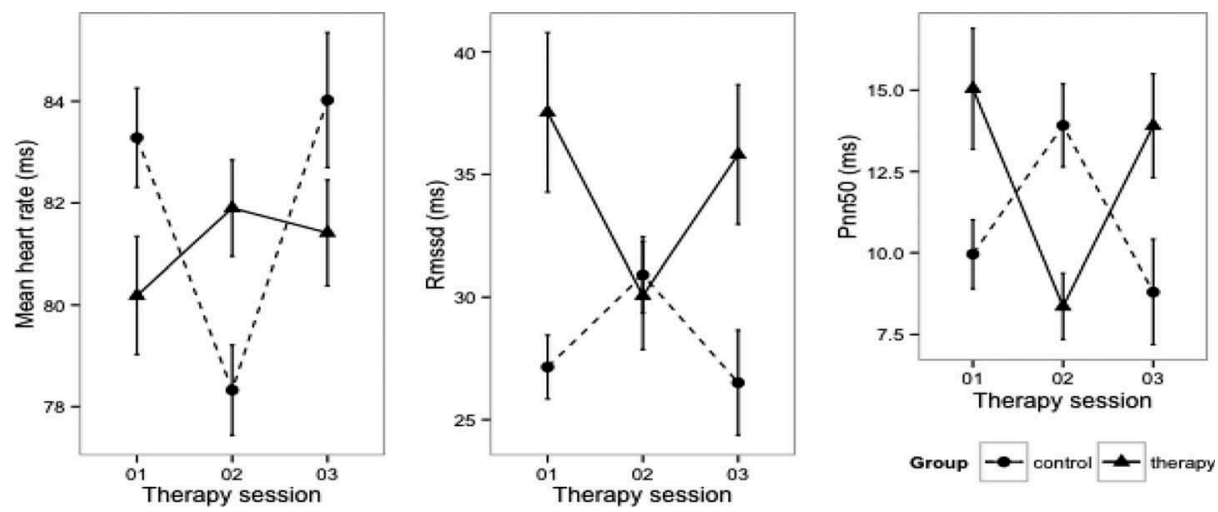

Figure 4. Changes in mean heart rate, RMSSD, and pNN50 in moderately anxious participants.

Note. The variation of mean heart rate, RMSSD and pNN50. Mean values $( \pm S E M)$ of the moderately anxious subgroup in the three therapy or control sessions. 
groups $[F(1,118)=0.27, p=.60]$. In contrast, the moderately anxious participants reported no change in the levels of anxiety and stress.

\section{Discussion}

This study aimed to assess changes in stress and anxiety in hospitalized pregnant women both with HRV and with questionnaires with respect to receiving live music therapy. We succeeded in collecting a valuable and unique set of data combining repeated physiological measurements and assessments of self-reported stress and anxiety in pregnant women. We found positive effects of live music therapy on the HRV in this group of participants. The data did not directly support the first hypothesis: in general, HRV was not significantly greater in the group of women who were randomly assigned to the live music therapy group. However, out of the 12 HRV measures only SD2 increased during the music therapy session, which may indicate that live music therapy helped the pregnant hospitalized women to relax more during the therapy session. This is an interesting result which is in line with previous research showing that music therapy increases HRV and can thus reduce anxiety in pregnant women (Bauer et al., 2010; Sidorenko, 2000; Yang et al., 2009). It is important to note that the relaxation of the mother during the late part of the pregnancy, and especially in complicated pregnancies as in the case of the participants in this study, is extremely important for a good birth outcome. For this reason, any method that can be safely used to help the relaxation of these mothers is medically relevant and useful. The results also show that effects can be observed already in a short time period of 20-30 min.

When considering the longer-term effects of live music therapy, that is, effects that occur from one session to the next, our hypothesis was not directly supported by the data. LF indicated that the participants were more relaxed on successive live music therapy sessions, which has also been found in previous studies, whereas the other measures did not support the hypothesis. Thus, we were not directly able to conclude the cumulative beneficial effects of participating in the music therapy on three consecutive days, even though one of the measures suggested a positive session-tosession effect. On the basis of this study, we cannot conclude whether repetition enhances the effect of music therapy. Rather, the effect might be partially temporary: Even though the women become relaxed during the therapy, by the next day they might be anxious again because of their worries and the hospital environment. The results comparing the three sessions might reflect differences in the baseline HRV of each day instead of the pure effect of music therapy, since only the data of the different therapy/rest sessions from the whole intervention were included in the analysis. In addition, the physiological responses in pregnant women may be suppressed compared to non-pregnant women, as some studies found no physiological response at all, although the self-reported anxiety was relieved (Chang \& Chen, 2005; DiPietro, Mendelson, Williams, \& Costigan, 2012). Additionally, the women with higher gestational age may have experienced more stress (Dennis et al., 2017).

The self-reported anxiety was significantly reduced in both the music therapy and control groups, but there was no difference in the amount of reduction. Moreover, when the groups were further divided by their initial level of anxiety to groups of high and moderate anxiety, no significant differences were found between the music therapy and control groups. The perceived stress was not found altered in any of the 
comparisons. The reduction in the perceived stress may have resulted from the progression of the pregnancy, reducing the risk of premature birth and severe complications. It should also be noted that the condition of our participants varies highly from one day to the next especially when the health of the fetus or the mother changes abruptly. This may have resulted in high deviation in the self-reported stress and anxiety in our patients, and such variation may possibly be much larger than that caused by live music therapy.

In some previous studies, pregnant women have reported lower levels of stress and anxiety following a music therapy intervention (Chang et al., 2008), whereas other studies report no change in the anxiety levels (Toker \& Kömürcü, 2017). In the current study, the questions concerning the self-reported stress might have been too general ("in the past two weeks"), and the questions about anxiety too bound to the specific moment to reflect the relaxing effect of the three short music therapy sessions. The results might have been different if we had instructed the pregnant women to fill in the forms right after the music therapy session. In our study, they had the opportunity to fill in the questionnaires one day later.

It was assumed that the stress experienced by the participants is mostly an acute reaction to the hospitalization and the health issues of the mother and the fetus. We did not assess chronic stress factors, which may nevertheless have contributed to the complications in the pregnancy and also to the stress levels during the inpatient care (Paarlberg, Vingerhoets, Passchier, Dekker, \& Van Geijn, 1995).

\section{Study limitations}

Unfortunately, despite the random assignment into the groups, the initial selfreported anxiety in the music therapy group was slightly higher than in the control group, which may have affected the comparability of the groups. Moreover, the participants' musical involvement or training was not asked, and musicians and nonmusicians may have different physiological responses to music (Bernardi, Porta, \& Sleight, 2006). However, none of the participants reported a music-related profession.

In the music therapy group the music therapist was present during the whole therapy session whereas the participants in the control group were left alone and asked to rest in their bed. However, five of the participants in the control group were once found at the end of the resting time speaking on the phone, one participant was watching TV, one was knitting and one had family members visiting.

Another limitation of the study is the dropout rate, which was not possible to avoid due to the situation of the participants. The electrodes of the HRV measurement device caused skin irritation for a fairly large number of women. If nonirritating electrodes could be used the women would presumably wear the device longer. The missing data points were taken into account in the statistical analysis. Also, breathing has been found to affect HRV (Billman, 2011), but in this study we chose not to control breathing, in order to focus on the effects of music therapy and not on those of guided breathing.

We did not collect more specific details or diagnosis from the medical records of the participants. This might be one more limitation of the study. On the other hand, 
the amount or type of anxiety and stress are not necessarily bound to the medical condition of the mother or fetus. Thus, they probably have no or a minor effect on the mother-fetus connection in this context.

\section{Recommendations for clinical practice}

The personnel on the ward appreciated the opportunity to offer patients music therapy given by a trained music therapist as a non-pharmacological option that may help the women relax as well as relieve stress and anxiety. High-risk pregnant women, and their infants (fetuses) are at real risk of experiencing trauma, and may face various future medical complications connected to the infant neural development, psycho-emotional development and the parent-infant attachment patterns. It is of utmost importance that pregnant women in the hospital find ways to relax. Providing music therapy to this population is aimed to prevent the high-risk pregnancy and the premature birth from becoming a traumatic event, and to help parents to cope better in this fragile situation. Music therapy can provide a break from the hypervigilance which is especially harmful when continuous. Music therapy could therefore be used in the future as common practice for pregnant women on the ward.

On the basis of this study and other previous studies, it would be a good practice for hospital personnel to assess the stress levels of their patients on a regular basis and actively offer music therapy: live music when available, or recorded music. This would ensure that the patients who are open to receive music therapy have the opportunity to do so.

Receptive music therapy does not require physical activity or much mental energy from the patient, so it is easy to implement even in the challenging situations the pregnant women are facing. Music therapy could also be used outside the hospital environment, in outpatient care or even at home.

\section{Suggestions for further studies}

It would be important to assess the long-term effects of live music therapy, perhaps with more therapy sessions and including a longitudinal design, so that the development and health of both the mother and the child could be assessed for one year after delivery. It could be useful to include a baseline measurement of the HRV in the analysis and a follow-up measurement some time after the end of the therapy. The control group could receive an alternative intervention for relaxation in order to compare the benefits of music therapy to other relaxation methods. In the present study, the empathetic presence of the music therapist may in itself have given the participants the experience of being nurtured, whereas the music therapist was not present with the resting control group. The study also prompted new research questions, such as whether music therapy influences the fetal HRV, and whether music therapy could help to relax when suffering from premature contractions, or having troubles with or anxiety related to breastfeeding.

\section{Conclusions}

The SD2 HRV measured from pregnant hospitalized women increased during live music therapy sessions, which may indicate that live music therapy helped the 
women to relax. Relaxation is important especially for women suffering from pregnancy complications, since relieving stress can promote the wellbeing of the mother and the fetus. Therefore, it is recommended that music therapy is offered for pregnant women.

\section{Acknowledgments}

Grant support for this study was received from Signe and Ane Gyllenberg Foundation. The funder had no role in the study design, data collection and analysis, decision to publish, or preparation of the manuscript.

\section{Disclosure statement}

The authors of the study declare that they have no conflict of interest regarding the study.

\section{Notes on contributors}

Pia Teckenberg-Jansson, music therapist, got her music therapy education and exam at the Musiktherapeutische Arbeitsstätte in Berlin, Germany, in 2004. She is working in Helsinki on an antenatal ward with pregnant women, in various nursing homes for elderly suffering from dementia and also in palliative care. Previous research projects of music therapy for prematurely born children.

Siiri Turunen received her Master of Psychology degree at University of Helsinki, Finland, in 2016, and her M.Phil. degree in cognitive science in 2013. She is currently working as a clinical psychologist at a psychiatric hospital. She has also worked among children and families.

Tarja Pölkki, R.N., Ph.D., Adjunct Professor, is working as a specialist in clinical nursing science in the unit of Children and Women in the Oulu University Hospital, Finland. Her research interests include pain assessment and pain management, focused especially on non-pharmacological methods, among pediatric patients, as well as family-centered care. Tarja is also a member of PEARL (Pain in Early Life) research group.

Minna-Johanna Lauri-Haikala received her Master of Psychology degree from University of Helsinki, Finland, in 2016. She is currently working as a school psychologist. She has also worked at a children's hospital.

Jari Lipsanen received his Master of Psychology degree from University of Helsinki, Finland, in 2006. Currently working as lecturer of psychometrics in Department of Psychology and Logopedics, in University of Helsinki.

Andreas Henelius received his D.Sc. (Tech.) degree in computer science from Aalto University in 2017. His current research interests include the use of randomization methods in data mining.

Ansa Aitokallio-Tallberg M.D., Ph.D. Specialist in Obstetrics, Gynecology and Perinatology Working as senior consultant on department of Obstetrics and Gynecology at University hospital in Helsinki.

Satu Pakarinen received her Doctor of Psychology degree from University of Helsinki, Finland, in 2011. Her current research focuses on measuring the effects of acute and prolonged stress on human physiology and performance as well as on health and wellbeing.

Marianne Leinikka received her M.Sc. (Tech.) degree in bioinformation technology from Aalto University, School of Electrical Engineering, in 2014. Her expertise is in the experimental work in physiological measurements both in laboratory as well as real-life settings and in the analysis of them. 
Minna Huotilainen is a Professor of Educational Sciences at University of Helsinki, Finland. She is best known for her work in studying auditory brain responses in infants and fetuses and showing the benefits of musical training for children and adolescents as well as for her studies on neuroscience of work.

\section{References}

Arnon, S., Shapsa, A., Forman, L., Regey, R., Bauer, S., Litmanovitz, I., \& Dolfin, T. (2006). Live music is beneficial to preterm infants in the neonatal intensive care unit environment. Birth, 33(2), 131-136.

Baayen, R. H., Davidson, D. J., \& Bates, D. M. (2008). Mixed-effects modeling with crossed random effects for subjects and items. Journal of Memory and Language, 59(4), 390-412.

Bailey, L. M. (1983). The effects of live music versus tape-recorded music on hospitalized cancer patients. Music Therapy, 3(1), 17-28.

Bastani, F., Hidarnia, A., Kazemnejad, A., Vafaei, M., \& Kashanian, M. (2005). A randomized controlled trial of the effects of applied relaxation training on reducing anxiety and perceived stress in pregnant women. Journal of Midwifery \& Women's Health, 50(4), e36-e40. doi:10.1016/j.jmwh.2004.11.008.

Bauer, C., Victorson, D., Rosenbloom, S., Barocas, J., \& Silver, R. (2010). Alleviating distress during antepartum hospitalisation: A randomised, controlled trial of music and recreation therapy. Journal of Women's Health, 19(3), 523-530.

Benedek, R. The tao-instruments from Benedek. Retrieved from https://www.aeterherz.de/start seite/english/

Bernardi, L., Porta, C., \& Sleight, P. (2006). Cardiovascular, cerebrovascular, and respiratory changes induced by different types of music in musicians and non-musicians: The importance of silence. Heart (British Cardiac Society), 92(4), 445-452.

Berntson, G. G., Thomas Bigger, J., Eckberg, D. L., Grossman, P., Kaufmann, P. G., Malik, M., ... van der Molen, M. W. (1997). Heart rate variability: Origins, methods, and interpretive caveats. Psychophysiology, 34(6), 623-648.

Bieligmeyer, S. (2015). Klangraum Körper - Einfluss einer musiktherapeutischen Intervention mit der Klangliege auf Resilienz und Wohlbefinden in der Onkologie [Effects of a sound-bed-intervention on psychological well-being and resilience in oncology](Unpublished doctoral dissertation). University of Tübingen, Germany.

Billman, G. E. (2011). Heart rate variability - a historical perspective. Frontiers in Physiology, 2, 86.

Billman, G. E. (2013). The LF/HF ratio does not accurately measure cardiac sympatho-vagal balance. Frontiers in Physiology, 4. doi:10.3389/fphys.2013.00026.

Brennan, M., Palaniswami, M., \& Kamen, P. (2001). Do existing measures of Poincare plot geometry reflect nonlinear features of heart rate variability? IEEE Transactions on Biomedical Engineering, $48(11), 1342-1347$.

Burrai, F., Hasan, W., Fancourt, D., Luppi, M., \& DiSomma, S. (2016). A randomized controlled trial of listening to recorded music for heart failure patients: Study protocol. Holistic Nursing Practice, 30(2), 102-115.

Calderon-Margalit, R., Qiu, C., Ornoy, A., Siscovick, D. S., \& Williams, M. A. (2009). Risk of preterm delivery and other adverse perinatal outcomes in relation to maternal use of psychotropic medications during pregnancy. American Journal of Obstetrics and Gynecology, 201(6), 579.e1-8. doi:10.1016/j.ajog.2009.06.061.

Carolan, M., Barry, M., Gamble, M., Turner, K., \& Mascareñas, O. (2012). The limerick lullaby project: An intervention to relieve prenatal stress. Midwifery, 28(2), 173-180.

Carrasco, M. J., Gaitán, R., González, O., \& Yánez, S. (2001). Correlation among Poincare plot indexes and time and frequency domain measures of heart rate variability. Journal of Medical Engineering \& Technology, 25(6), 240-248.

Chang, H., Yu, C., Chen, S., \& Chen, C. (2015). The effects of music listening on psychosocial stress and maternal-fetal attachment during pregnancy. Complementary Therapies in Medicine, 23(4), 509-515.

Chang, M., Chen, C., \& Huang, K. (2008). Effects of music therapy on psychological health of women during pregnancy. Journal of Clinical Nursing, 17(19), 2580-2587. 
Chang, S.-C., \& Chen, C.-H. (2005). Effects of music therapy on women's physiologic measures, anxiety, and satisfaction during cesarean delivery. Research in Nursing \& Health, 28(6), 453-461.

Chuang, L.-L., Lin, L.-C., Cheng, P.-J., Chen, C.-H., Wu, S.-C., \& Chang, C.-L. (2012a). Effects of a relaxation training programme on immediate and prolonged stress responses in women with preterm labour. Journal of Advanced Nursing, 68(1), 170-180. doi:10.1111/j.1365-2648.2011.05765.x.

Chuang, L.-L., Lin, L.-C., Cheng, P.-J., Chen, C.-H., Wu, S.-C., \& Chang, C.-L. (2012b). The effectiveness of a relaxation training program for women with preterm labour on pregnancy outcomes: A controlled clinical trial. International Journal of Nursing Studies, 49(3), 257-264. doi:10.1016/j.ijnurstu.2011.09.007.

Cohen, S., Kamarck, T., \& Mermelstein, R. (1983). A global measure of perceived stress. Journal of Health and Social Behavior, 24(4), 385-396.

Collins Cook, E. (2012). The uses of music and music therapy to decrease stress and anxiety during pregnancy (Unpublished master's thesis). Faculty of the College of Nursing and Health Professions Drexel University, Philadelphia, PA.

Corbijn van Willenswaard, K., Lynn, F., McNeill, J., McQueen, K., Dennis, C.-L., Lobel, M., \& Alderdice, F. (2017). Music interventions to reduce stress and anxiety in pregnancy: A systematic review and meta-analysis. BMC Psychiatry, 17, 271. doi:10.1186/s12888-017-1432-x.

Delaney, J. P. A., \& Brodie, D. A. (2000). Effects of short-term psychological stress on the time and frequency domains of heart-rate variability. Perceptual and Motor Skills, 91(2), 515-524.

Dennis, C. L., Falah-Hassani, K., \& Shiri, R. (2017, May). Prevalence of antenatal and postnatal anxiety: Systematic review and meta-analysis. The British Journal of Psychiatry, 210(5), 315-323. doi:10.1192/bjp.bp.116.187179.

Dipietro, J. A., Costigan, K. A., Nelson, P., Gurewitsch, E. D., \& Laudenslager, M. L. (2008). Fetal responses to induced maternal relaxation during pregnancy. Biological Psychology, 77, 11-19.

DiPietro, J. A., Hodgson, D. M., Costigan, K. A., Hilton, S. C., \& Johnson, T. R. (1996). Fetal neurobehavioral development. Child Development, 67(5), 2553-2567. Retrieved from http://www. ncbi.nlm.nih.gov/pubmed/9022256.

DiPietro, J. A., Mendelson, T., Williams, E. L., \& Costigan, K. A. (2012). Physiological blunting during pregnancy extends to induced relaxation. Biological Psychology, 89(1), 14-20.

Dole, N., Savitz, D. A., Hertz-Picciotto, I., Siega-Riz, A. M., McMahon, M. J., \& Buekens, P. (2003). Maternal stress and preterm birth. American Journal of Epidemiology, 157(1), 14-24.

Douglas, A. J. (2010). Baby on board: Do responses to stress in the maternal brain mediate adverse pregnancy outcome? Frontiers in Neuroendocrinology, 31(3), 359-376. doi:10.1016/j.yfrne.2010.05.002.

Eckberg, D. L. (1997). Sympathovagal balance. Circulation, 96(9), 3224-3232.

Garunkstiene, R., Buinauskiene, J., Ingrida Ulozienec, I., \& Markuniene, E. (2014). Controlled trial of live versus recorded lullabies in preterm infants. Nordic Journal of Music Therapy, 23(1), 71-88. doi:10.1080/08098131.2013.809783.

Geller, P. A. (2004). Pregnancy as a stressful life event. CNS Spectrums, 9(3), 188-197. Retrieved from http://www.ncbi.nlm.nih.gov/pubmed/14999159.

Gilboa, A. (2014). The dual nature of the womb and its implications for music therapy. Nordic Journal of Music Therapy, 23(3), 242-262. doi:10.1080/08098131.2013.809784.

Graignic-Philippe, R., \& Tordjman, S. (2009). Effets du stress pendant la grossesse sur le développement du bébé et de l'enfant [Effects of stress during pregnancy on infant and child development]. Archives De Pédiatrie, 16(10), 1355-1363.

Henelius, A. (2014). Colibri: Platform for automating analyses of physiological time series in $\mathrm{R}$. R-package version 0.1.2. Retrieved from https://github.com/bwrc/colibri.

Karmakar, C. K., Khandoker, A. H., Gubbi, J., \& Palaniswami, M. (2009). Complex correlation measure: A novel descriptor for Poincaré plot. Biomedical Engineering Online, 8(1), 17.

Kaufmann, J. (2014). Musiktherapie mit risikoschwangeren Frauen [Music therapy treatment options for women with high-risk pregnancies]. In J. Kaufmann, R. Nussberger, M. Esslinger, \& M. M. Leitgeb (Eds.), Gespürt - gehört - gebor(g)en. Musiktherapie mit risikoschwangeren Frauen, Säuglingen und Kleinkindern [Felt - heard - born(e). Music therapy for women with highrisk pregnancies, infants and small children] (pp. 9-68). Wiesbaden: Reichert.

Kemper, K. J., \& Danhauer, S. C. (2005). Music as therapy. Southern Medical Journal, 98(3), 282-288. 
Lai, H. L., \& Li, Y. M. (2011). The effect of music on biochemical markers and self perceived stress among first-line nurses: A randomized controlled crossover trial. Journal of Advanced Nursing, 67(11), 2414-2424.

Lin, M. F., Hsieh, Y., Hsu, Y., Fetzer, S., \& Hsu, M. (2011). A randomised controlled trial of the effect of music therapy and verbal relaxation on chemotherapy-induced anxiety. Journal of Clinical Nursing, 20(7-8), 988-989.

Lobel, M., Cannella, D. L., Graham, J. E., DeVincent, C., Schneider, J., \& Meyer, B. A. (2008). Pregnancyspecific stress, prenatal health behaviors, and birth outcomes. Health Psychology, 27(5), 604-615.

Maloni, J. A., \& Park, S. (2005). Postpartum symptoms after antepartum bed rest. Journal of Obstetric, Gynecologic \& Neonatal Nursing, 34(2), 163-171.

Melillo, P., Bracale, M., \& Pecchia, L. (2011). Nonlinear heart rate variability features for real-life stress detection. Case study: Students under stress due to university examination. Biomedical Engineering Online, 10(1), 96.

Mulder, E. J., Robles de Medina, P., Huizink, A., Van Den Bergh, B. R. H., Buitelaar, J., \& Visser, G. H. (2002). Prenatal maternal stress: Effects on pregnancy and the (unborn) child. Early Human Development, 70(1-2), 3-14. doi:10.1016/S0378-3782(02)00075-0.

Nussberger, R. (2014). Impuls-Musiktherapie mit hospitalisierten risikoschwangeren Frauen und ihren ungeborenen Kindern [Short-term music therapy involving hospitalised women with highrisk pregnancies and their unborn children]. In J. Kaufmann, R. Nussberger, M. Esslinger, \& M. M. Leitgeb (Eds.), Gespürt - gehört - gebor(g)en. Musiktherapie mit risikoschwangeren Frauen, Säuglingen und Kleinkindern [Felt - hear - born(e). Music therapy for women with high-risk pregnancies, infants and small children] (pp. 69-128). Wiesbaden: Reichert.

Paarlberg, K. M., Vingerhoets, A. J. J. M., Passchier, J., Dekker, G. A., \& Van Geijn, H. P. (1995). Psychosocial factors and pregnancy outcome: A review with emphasis on methodological issues. Journal of Psychosomatic Research, 39(5), 563-595.

Pesonen, A., Räikkonen, K., Heinonen, K., Komsi, N., Järvenpää, A., \& Strandberg, T. (2008). A transactional model of temperamental development: Evidence of a relationship between child temperament and maternal stress over five years. Social Development, 17(2), 326-340.

$\mathrm{R}$ Development Core Team (2014). R: A language and environment for statistical computing. $\mathrm{R}$ Foundation for Statistical Computing, Vienna, Austria. Retrieved from https://www.R-project.org/.

Räikkönen, K., Pesonen, A.-K., Heinonen, K., Kajantie, E., Hovi, P., Järvenpää, A.-L., ... Andersson, S. (2008). Depression in young adults with very low birth weight: The Helsinki study of very low-birth-weight adults. Archives of General Psychiatry, 65(3), 290-296. doi:10.1001/archgenpsychiatry.2007.40.

Reinhold, S. (2012). Anthroposophical Music therapy. Filderstadt: Verlag Freie Ausbildung.

Sacha, J. (2013). Why should one normalize heart rate variability with respect to average heart rate. Frontiers in Physiology, 4. doi:10.3389/fphys.2013.00306.

Scargle, J. (1982). Studies in astronomical time series analysis. II-Statistical aspects of spectral analysis of unevenly spaced data. The Astrophysical Journal, 263, 835-853.

Shaffer, F., \& Ginsberg, J. P. (2017). An overview of heart rate variability metrics and norms. Frontiers in Public Health, 5, 258.

Sidorenko, V. N. (2000). Clinical application of medical resonance therapy music in high-risk pregnancies. Integrative Physiolocigal and Behavioral Science, 35(3), 199-207.

Sinclair, J., Taylor, P. J., \& Hobbs, S. J. (2013). Alpha level adjustments for multiple dependent variable analyses and their applicability - A review. International Journal of Sports Science and Engineering, 7(1), 17-20.

Soleimani, F., Zaheri, F., \& Abdi, F. (2014, Jun). Long-term neurodevelopmental outcomes after preterm birth. Iran Red Crescent Medical Journal, 16(6), e17965. doi:10.5812/ircmj.17965.

Spielberger, C., Gorsuch, R., \& Lushene, R. (1970). STAI manual for the state-trait anxiety inventory. Palo Alto, CA: Consulting Psychologists.

Taelman, J., Vandeput, S., Vleminck, E., Spaepen, A., \& Van Huffel, S. (2011). Instantaneous changes in heart rate regulation due to mental load in simulated office work. European Journal of Applied Physiology, 111(7), 1497-1505.

Task Force of the European Society of Cardiology and the North American Society of Pacing and Electrophysiology. (1996). Heart rate variability: Standards of measurement, physiological interpretation and clinical use. Circulation, 93 (1043-1065). doi:10.1161/01.CIR.93.5.1043. 
Toker, E., \& Kömürcü, N. (2017). Effect of Turkish classical music on prenatal anxiety and satisfaction: A randomized controlled trial in pregnant women with pre-eclampsia. Complementary Therapies in Medicine, 30, 1-9.

Tulppo, M. P., Makikallio, T. H., Takala, T. E., Seppanen, T. H. H. V., \& Huikuri, H. V. (1996). Quantitative beat-to-beat analysis of heart rate dynamics during exercise. American Journal of Physiology-Heart and Circulatory Physiology, 271(1), H244-H252.

Van den Bergh, B., Mulder, E., Mennes, M., \& Glover, V. (2005). Antenatal maternal anxiety and stress and the neurobehavioural development of the fetus and child: Links and possible mechanisms. A review. Neuroscience and Biobehavioral Reviews, 29(2), 237-258.

Xu, X., \& Schuckers, S. (2001). Automatic detection of artifacts in heart period data. Journal of Electrocardiology, 34(4), 205-210.

Yang, M., Li, L., Zhu, H., Alexander, I. M., Liu, S., Zhou, W., \& Ren, X. (2009). Music therapy to relieve anxiety in pregnant women on bedrest: A randomized, controlled trial. $M C N$ : The American Journal of Maternal/Child Nursing, 34(5), 316-323. 